\title{
Fracture of Limbs Bones in a Town in Post Conflict (Case of Bukavu Town)
}

\author{
Toha Georges Kuyigwa ${ }^{1}$, Ona Longombe Ahuka ${ }^{2}$, Namugusha Alain Kabakuli ${ }^{1}$, \\ Jeff Maotela Kabinda ${ }^{1}$, Akinja Bitum Uwonda ${ }^{3}$ \\ ${ }^{1}$ Medical School, Catholic University of Bukavu, Bukavu, Democratic Republic of Congo \\ ${ }^{2}$ Medical School of Kisangani, Kisangani, Democratic Republic of Congo \\ ${ }^{3}$ Medical School of Mbuji Mayi, Mbuji Mayi, Democratic Republic of Congo \\ Email: kuyigwa2002@yahoo.fr
}

Received 19 August 2015; accepted 6 November 2015; published 9 November 2015

Copyright (C) 2015 by authors and Scientific Research Publishing Inc.

This work is licensed under the Creative Commons Attribution International License (CC BY). http://creativecommons.org/licenses/by/4.0/

(c) (7) Open Access

\section{Abstract}

Background: Rapid urbanization and increasing fleet in low-income countries are the basis of the higher rate of trauma and fractures. In a post conflict environment, the abnormal movement of firearms and poverty from them may change the configuration's epidemiological, anatomical and clinical fractures of the limbs bones as well as their care. Goal: To make an inventory on the fractures of the limb bones in Bukavu town, a town in post armed conflict. Method: This work is transversal, retrospective and descriptive on 500 fractures of the limbs bones recorded on a period of 3 months from $1^{\text {st }}$ June to $31^{\text {st }}$ August 2013. Twenty investigators went around different places of Bukavu town to interview and complete a research protocol ad hoc. In total, we recorded 500 subjects with 570 fractures of the limb bones. Results: The average age is 29.4 years old and $37 \%$ are male fractured. The main circumstances of occurrence of the fracture of the limbs bones are the falls (31.7\%), firearms $(22.2 \%)$ followed closely by road traffic accidents $(21.9 \%)$. Students (38.6\%) and the unemployed $(29.4 \%)$ are most victims' fractures of limb bones. The forearm bones $(31.7 \%)$ and leg bones $(27.2 \%)$ are most concerned, $52.2 \%$ fractured turned to modern medicine against $\mathbf{4 1 . 8 \%}$ for traditional medicine. Conclusion: The fractures of the limbs bones in Bukavu mainly concern young male subjects. They occur with the waning of a fall and preferentially affect the bones of the forearm. Good governance would reduce the incidence of fractures of the limbs bones and their assessment.

\section{Keywords}

Fractures of the Limbs Bones, Young Male People, A Town in Post Conflict 


\section{Introduction}

A fracture is a common lesion defined as rupture of bone's continuity. It is a consequence of trauma and occurs in a lot of circumstances. It necessitates a good support, and otherwise it exposes to varying degree of complications obscuring at short- or long-term functional, sociological, economic, psychological outcome, if the victim does not succumb to his injury. In the world, the trauma has become a major cause of death and disability. In 2002, it was estimated that 1.2 million people were killed and 50 million were injured in road traffic accidents worldwide [1]. If it is true that the rates of consecutive limbs fractures to falls and road traffic accidents are decreasing in most high-income countries (500/100,000 per year), it is getting higher in middle- and low-income countries ranging from 1000 to 2600/100,000 per year [2]. Several factors contributing to the emergence of trauma in low-income countries are: rapid urbanization, poor road conditions, sharing the same spaces for vehicles and pedestrians, poorly trained drivers, driving under the influence of alcohol, and lack of respect for traffic rules [3]. Naddumba et al. [3] in Uganda noticed 39\% of all injuries, primarily in males aged 16 - 44 years. They are a result of rapid motorization and urbanization in a country with poor economy. The province of South Kivu in the Democratic Republic of Congo (DRC) experienced recurrent wars for over 15 years. This period was characterized by a proliferation of armed groups with a consequent abnormal movement of firearms [4] [5]. This state of insecurity is likely to change the demographic profile and clinic pathological fractures in this region and their care. No work on the urban scale on fractures of limb bones has been conducted in Bukavu town. This work aims at studying the determinants of fractures of the limbs bones in this town in order to highlight the priorities that can help in prevention planning and care.

\section{Methodology}

\subsection{Environment of Study}

This study was conducted in the Bukavu town, county town of South Kivu province located $2000 \mathrm{~km}$ from Kinshasa, capital of Democratic Republic of Congo (DRC). With an area of $60 \mathrm{~km}^{2}$ and a population estimated at 876,916 inhabitants (density: 14,615/ $\mathrm{km}^{2}$ ), Bukavu has three townships namely Ibanda, Bagira and Kadutu. The age group of 15 - 49 years old is $44.4 \%$ of the population. The informal trade, generally represents the bulk of the job market.

On the security front, South Kivu province is experiencing political and social instability related to the presence of armed groups on the basis of population displacements with all the consequences (rape, looting, killings and destruction of infrastructure). The overcrowded of Bukavu town and the uncontrolled buildings resulting from the subsequent rural exodus insecurity. The automotive cartage consists of 26,161 vehicles and 4525 motorcycles rolling on a road of $88 \mathrm{~km}$ (297 vehicles $/ \mathrm{km}$ ) distributed as follows: $64.5 \mathrm{~km}$ of asphaltered roads in which 62\% built in colonial period (before 1960) and thus dilapidated and $23.5 \mathrm{~km}$ dirt.

\subsection{Type of Study}

This is a transversal and retrospective descriptive study of the full extent of Bukavu town in $1^{\text {st }}$ June to $31^{\text {st }} \mathrm{Au}-$ gust 2013. Twenty investigators divided into 4 groups were deployed in three townships of the town to identify cases which have been experienced a fracture. We have used the method of semi structured interviews including open questions. The investigators addressed to the chiefs of street avenues to show them the homes in which one or more families have experienced limbs fracture. On consent of the interviewed, the investigators recorded the following parameters: age, sex, circumstances of fracture, broken bones and type of medicine in which the interviewee had resorted.

\subsection{Study Population}

\subsubsection{Inclusion Criteria}

Have been selected for our study any subject that experienced the fracture of limbs bones living in Bukavu town during the investigation period and found at his/her home during the visit, patient having at least one radiograph.

\subsubsection{Exclusion Criteria}

Not included in this study any subject who experienced a fracture met during the visit but does not live in Bu- 
kavu town, fractured patient living in Bukavu and missing from his/her home during the investigation, patient flatly refused to participate to our study or else coined the interview, patient missing radiographs. In total, we recorded 500 subjects with 570 fractures of limb bones in the three townships, 35 interviewed having more than one fracture.

\subsection{Statistical Analysis}

The data were compiled and analyzed using the software Epi Info version 3.5.4 and Microsoft Word and Excel. Statistical analyzes were summarized in proportions for categorical variables and the average for the age variable.

\section{Results}

\subsection{Main Features}

One hundred and eighty five (37\%) of the fractured limb bones are in the age group of 16 - 30 years old and 409 (81.8\%) are aged less than 45 years old. The mean is 29.4 years old the standard deviation being 17.87 . Three hundred and eighty four (77\%) subjects were male with a sex ratio of 3:1. Regarding the profession, 193 (38.6\%) respondents are the students, 147 (29.4\%) are unemployed and 61 (12.2\%) are soldiers.

\subsection{Causes of Fractures}

In a total of 570 fractures recorded, 181 (31.8\%) are caused by falls, 127 (22.3\%) by firearms and 125 (21.9\%) by road traffic accidents (RTA).

\subsection{Broken Bones}

As far as the broken bone is concerned, the forearm bones come first with 160 (28.1\%) followed closely by the leg bones 155 (27.2\%) (Figure 2).

\subsection{Kind of Medicine}

Regarding the type of remedy, note that 261 (52.2\%) were fractured addressed exclusively to modern medicine (MM), 209 (41.8\%) have used the only traditional medicine (TM) while 26 (5.2\%) were treated with the two types of medicine (5.2\%).

\section{Discussion}

Our work has set an objective study of the fractures limbs bones in Bukavu town, a town in post armed conflict in order to identify the socio demographic profile, causes, broken bones and the type of medicine for their care. Our study presents methodical limits because some patients have not been recorded and others lacked exams attesting they have been fractured. These limits may influence the prevalence such as underestimation the results compared to reality. Nevertheless this study has its merit because it highlights the fracture map in the context of our town.

Table 1 mentions the main features of limbs bones fracture in Bukavu. Thirty seven per cent of fractured bones of the limbs are in the age group of 16 - 30 years old and $81 \%$ are aged less than 45 years old. Our results are similar to those of Naddumba EK in Uganda [3], but are different from those reported by other authors. Many authors believe that the incidence of fractures in a population is often bimodal, with peaks in the young population on the one hand and peaks in those of the third age [6]-[8] in the another hand. The mechanisms of these fractures are different in the two extremes of age; the violent trauma occurs in young subjects and adult males while in older women, minor trauma as falls, can result in pathological fractures favored by menopause [9]-[11]. The distribution of fractures of the limbs bones by age in our study is modal united for both men and women. The very limited life expectancy of the Congolese population justifies this distribution; it is 49 years old [12].

Seventy seven per cent of our patients are male with a sex ratio of 3:1. Our results are similar to literature data [3] [10] [13] [14]. The high frequency of fractures of limbs bones in young adult males is justified by the exposure 
Table 1. Main features.

\begin{tabular}{cccc}
\hline & $\mathrm{n}$ & $\%$ & Mean (SD) \\
\hline Age (years) & & & $29.4 \pm 17.87$ \\
\hline $0-15$ & 114 & 37 & \\
$16-30$ & 185 & 22 & 12.2 \\
$31-45$ & 110 & 6 & \\
$46-60$ & 61 & 77 & 23 \\
Over 60 & 30 & & \\
\hline Sex & 385 & 38.6 \\
M & 115 & 29.4 \\
F & 193 & 12.2 \\
\hline Profession & 147 & 9 \\
\hline Student & 61 & 6 \\
Unemployed & 45 & 3.8 \\
Soldier & 30 & & \\
State agent & 9 & & \\
Independent & & & \\
Company & & & \\
Other & & & \\
\hline
\end{tabular}

of this population to any kind of trauma.

Almost $37 \%$ of our patients are students followed by unemployed or $29.4 \%$. Our results are the same with that of Naddumba EK [3], because he records students in first position. The predominance of students in our work is related to the structure of the population which is dominated by youth attending schools. The proportion of the unemployed comes from the rural exodus. Indeed, insecurity in eastern DRC has led to a displacement of the rural population to the town secure meaningful because they house the state institutions [5] [15]. These jobless are actually unemployed wandering through the town in search of livelihood. El Tayeb S et al. in Sudan believe that low socioeconomic status is a risk factor for injuries in urban areas [16].

The circumstances of fractures occurrence are represented by falls (31.7\%), firearms (22.3\%) and RTA (29.1\%) as shown in Figure 1. These results remind those of other authors; road traffic accidents, falls, mechanical forces are typically the most involved in the occurrence of fractures [6] [12] [13]. The high rate of fractures of the limbs bones caused by the falls for a young population in our work is a singularity. Two factors explain this predominance. Firstly, Bukavu is a mountainous town with a highly rugged relief, high rainfall and a very slippery clay soil. Secondly, it is characterized by the uncontrolled construction ignoring urban standards. Entire neighborhoods are built without streets or roads, winding paths, steep and dotted path with holes are the only access roads to the homes. Fractures caused by firearms occupy the $2^{\text {nd }}$ place in our study. This high proportion of fractures caused by firearms is due to various wars and rebellions experienced by the Eastern DRC and the endemic insecurity in post conflict in this region [5]. Other authors have lambasted the perverse and incidentals of wars in eastern DRC in many domains. In the health sector, we can mention the sexual violence [17] [18]-[20] the Konzo's disease [21] and the malnutrition [22].

The bones of the forearm (31.7\%) and the bones of the leg (27.2\%) were the most frequently fractured. The authors' opinions are far from unanimous with regard to the distribution of fractures of limbs bones on the various parts of the body. For Berecki Gisolf-J [10] fractures of finger/toe, arm and the ankle are the most common. Like us, Mehrpour SR in Iran [7], ranks first bone fractures of the forearm. The prevalence of falls as a cause of fractures in our series reflects this allocation. During the fall, the victim uses his/her hands to cushion the blow that will be transmitted to the radius and ulna and fracturing these bones. The leg bones occupy the 2nd place in our work. This can be explained by the fact that the leg is equal to the impact by vehicles and bikes wheels in road traffic accidents.

According the kind of medicine, we note that $52.2 \%$ have addressed exclusively to the MM and $41.8 \%$ have only used the TM (Figure 3). Our rate of using traditional medicine is double of the $24.89 \%$ reported by Hoek- 


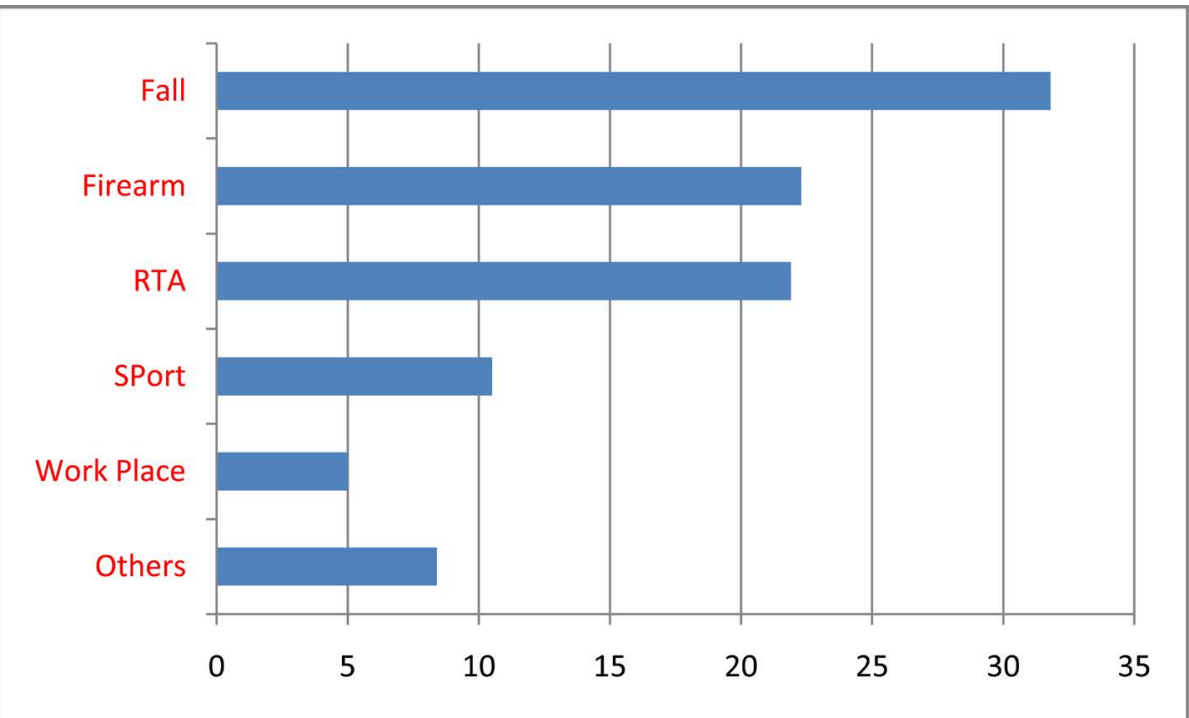

Figure 1. Causes of fractures.

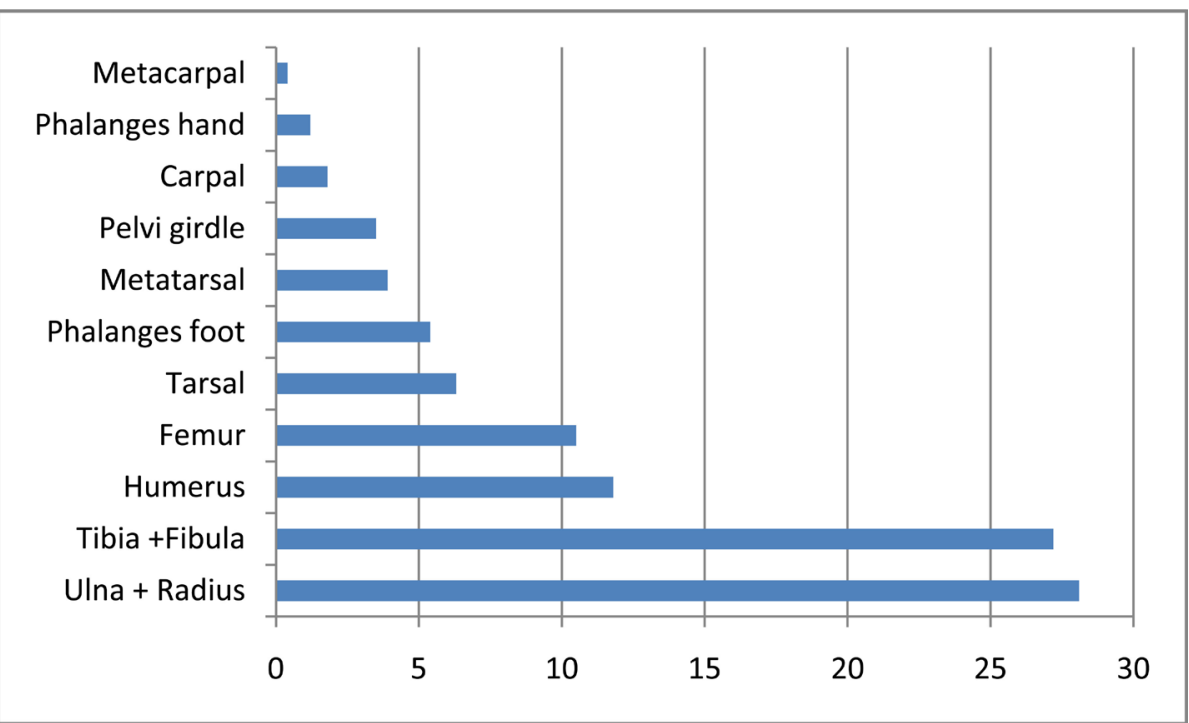

Figure 2. Broken bones.

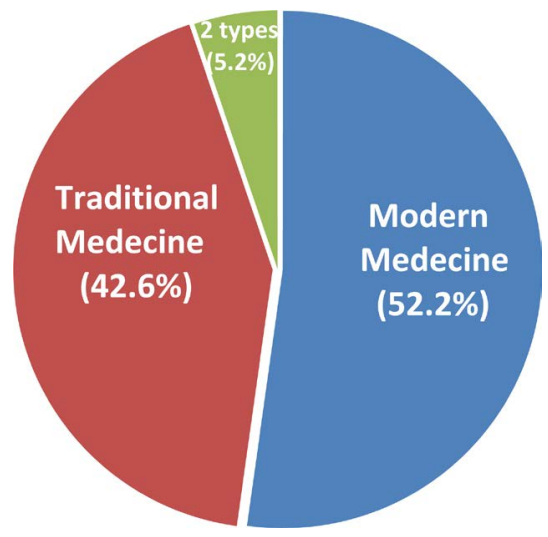

Figure 3. Kind of medicine. 
man et al. [23]. The use of traditional medicine is a real practice in space and in time [24]. Diakite et al. estimate that $85 \%$ of rural populations in developing countries are dependent on the TM for their health needs [25]. Without ignoring the importance of traditional medicine in the treatment of fractures, the complications arising from this practice are increasingly reported [26] [27]. For Ajibade A et al. in Nigeria, all causes of different amputation, consecutive gangrene to traditional medicine occupy the 2nd place (31.8\%) after the trauma (42.4\%) [27]. The use of traditional medicine in our study is somehow related to the fact of low income of South Kivu's citizens, the poverty rate being of $75.6 \%$ [28].

\section{Conclusion}

The fractures of limbs bones in Bukavu mainly concern young male subjects. They occur with the waning of a fall and firearms, and preferentially affect the bones of the forearm and leg bones. A rational planning of urbanization of the town, the pacification of the region, development of rolling roads for vehicles and sidewalks for pedestrians and strict enforcement of road safety measures would reduce the prevalence of fracture of the limbs bones in Bukavu town. A sensitization of the population on the complications of traditional medicine in the treatment of fractures is needed.

\section{References}

[1] Ameratunga, S., Hijar, M. and Norton, R. (2006) Road-Traffic Injuries: Confronting Disparities to Address a GlobalHealth Problem. Lancet, 367, 1533-1539. http://dx.doi.org/10.1016/S0140-6736(06)68654-6

[2] World Health Organization (2003) The Burden of Musculoskeletal Conditions at the Start of the New Millennium. Report of a WHO Scientific Group, WHO Technical Report Series 919, WHO, Geneva.

[3] Naddumba, E.K. (2008) Musculoskeletal Trauma Services in Uganda. Clinical Orthopaedics and Related Research, 466, 2317-2322. http://dx.doi.org/10.1007/s11999-008-0369-2

[4] Mushi, F.M. (2013) Insecurity and Local Governance in Congo’s South Kivu. IDS Bulletin, 44, 15-29. http://dx.doi.org/10.1111/1759-5436.12004

[5] Kuyigwa, T.G., Uwonda, A.B. and Ahuka, O.L. (2015) Fractures by Firearms in Conflict Town. Open Journal of Orthopedics, 5, 120-125. http://dx.doi.org/10.4236/ojo.2015.55016

[6] Sadat-Ali, M., Alomran, A.S., Azal, A., Al-Sayed, H.N., Al-Dhafer, B.A. and Kubbara, A.F. (2015) Epidemiology of Fractures and Dislocations among Urban Communities of Eastern Saudi Arabia. Saudi Journal of Medicine \& Medical Sciences, 3, 54-57. http://dx.doi.org/10.4103/1658-631X.149682

[7] Mehrpour, S.H., Nabian, M.H., Zanjani, L.O., Foroughmand-Araabi, M. and Kamrani, R.S. (2015) Descriptive Epidemiology of Traumatic Injuries in 18890 Adults: A 5-Year-Study in a Tertiary Trauma Center in Iran. Asian Journal of Sports Medicine, 6, e23129. http://dx.doi.org/10.5812/asjsm.23129

[8] Morrison, A., Fan, T., Sen, S.S. and Weisenfluh, L. (2013) Epidemiology of Falls and Osteoporotic Fractures: A Systematic Review. ClinicoEconomics \& Outcomes Research, 5, 9-18.

[9] Meling, T., Harboe, K. and Søreide, K. (2009) Incidence of Traumatic Long-Bone Fractures Requiring In-Hospital Management: A Prospective Age- and Gender-Specific Analysis of 4890 Fractures. Injury, 40, 1212-1219. http://dx.doi.org/10.1016/j.injury.2009.06.003

[10] Berecki-Gisolf, J., McClure, R., Seubsman, S. and Sleigh, A. (2012) Reporting of Lifetime Fractures: Methodological Considerations and Results from the Thai Cohort Study. BMJ Open, 2, e001000. http://dx.doi.org/10.1136/bmjopen-2012-001000

[11] Gerstl, S., Sauter, J., Kasanda, J. and Kinzelbach, A. (2013) Who Can Afford Health Care? Evaluating the SocioEconomic Conditions and the Ability to Contribute to Health Care in a Post-Conflict Area in DR Congo. PLoS ONE, 8, e77382. http://dx.doi.org/10.1371/journal.pone.0077382

[12] El Tayeb, S., Abdalla, S., Mørkve, O., Heuch, I. and Van den Bergh, G. (2014) Injuries in Khartoum State, the Sudan: A Household Survey of Incidence and Risk Factors. International Journal of Injury Control and Safety Promotion, 21, 144-153. http://dx.doi.org/10.1080/17457300.2013.792283

[13] Banchong, M. (2008) Musculoskeletal Trauma Service in Thailand. Clinical Orthopaedics and Related Research, 466, 2323-2328.

[14] Haghpanah, B. (2014) The Transforming Face of Fracture Epidemiology. Archives of Trauma Research, 3, Article ID: e23364.

[15] Morvan, H. (2005) Etude de cas: Jeunes, violence chronique et pauvreté dans les territoires d’Uvira-Fizi-Minembwe au 
Sud-Kivu (RDCongo). Promoting Livelihood and Coping Strategies of Groups Affected by Conflicts and Natural Disasters, 2, 89-143.

[16] El Tayeb, S., Abdalla, S., Heuch, I. and Van den Bergh, G. (2015) Socioeconomic and Disability Consequences of Injuries in the Sudan: A Community-Based Survey in Khartoum State. Injury Prevention, 21, 56-62. http://dx.doi.org/10.1136/injuryprev-2013-040818

[17] Steiner, B., Benner, M.T., Sondorp, E., Schmitz, K.P., Mesmer, U. and Rosenberger, S. (2009) Sexual Violence in the Protracted Conflict of DRC Programming for Rape Survivors in South Kivu. Conflict and Health, 3, 3. http://dx.doi.org/10.1186/1752-1505-3-3

[18] Mukwege, D.M. and Nangini, C. (2009) Rape with Extreme Violence: The New Pathology in South Kivu, Democratic Republic of Congo. PLoS Medicine, 6, Article ID: e1000204. http://dx.doi.org/10.1371/journal.pmed.1000204

[19] Bartels, S., Scott, J., Leaning, J., Mukwege, D., Lipton, R. and Van Rooyen, M. (2010) Surviving Sexual Violence in Eastern Democratic Republic of Congo. Journal of International Women's Studies, 11, 37-49.

[20] Onsrud, M., Sjøveian, S., Luhiriri, R. and Mukwege, D. (2008) Sexual Violence-Related Fistulas in the Democratic Republic of Congo. International Journal of Gynecology \& Obstetrics, 103, 265-269.

[21] Chabwine, J.N., Masheka, C., Balol'ebwami, Z., Maheshe, B., Balegamire, S. and Rutega, B. (2011) Appearance of Konzo in South-Kivu, a Wartorn Area in the Democratic Republic of Congo. Food and Chemical Toxicology, 49, 644649. http://dx.doi.org/10.1016/j.fct.2010.07.050

[22] Kandala, N., Madungu, T.P., Emina, J.B., Nzita, K.P.D. and Cappuccio, F.P. (2011) Malnutrition among Children under the Age of Five in the Democratic Republic of Congo (DRC): Does Geographic Location Matter? BMC Public Health, 11, 261. http://dx.doi.org/10.1186/1471-2458-11-261

[23] Hoekman, P., Oumarou, M.T. and Djia, A. (1996) Injuries Due to Motor Accidents: A Public Health Problem in Niamey. Medicine Black Africa, 43, 596-601.

[24] Stratégie de l’OMS pour la Médecine traditionnelle pour 2014-2023. http://thesesante.ups-tlse.fr/437/1/2014TOU31027.pdf

[25] Diakite, C., Mounkoro, P.P., Dougnon, A., Baiguini, G., Bonciani, M. and Giani, S. (2004) Study of Trauma Traditional in Dogon Country (Mali). Medical Mali, 19, 13-19.

[26] Tékpa, B.J.D., Ngongang, O.G.F., Keïta, K., Alumeti, D., Sané, A.D. and Diemé, C.B. (2013) Gangrene of Limb after a Traditional Treatment of Bamboo Splint Fractures in Children at Regional Hospital Kaolack (Senegal). Bulletin of the Society of Exotic Pathology, 106, 100-103. http://dx.doi.org/10.1007/s13149-013-0278-9

[27] Ajibade, A., Akinniyi, O.T. and Okoye, C.S. (2013) Indications and Complications of Major Limb Amputations in Kano, Nigeria. Ghana Medical Journal, 47, 185-188.

[28] Moummi, A. (2010) Working Paper 112-Analysis of Poverty in the Democratic Republic of Congo, No. 987. 